\title{
Dauven-van Knippenberg, Carla, Herberichs, Cornelia, Kiening, Christian, Medialität des Heils im späten Mittelalter
}

Ludovic Viallet

\section{(2) OpenEdition}

Journals

Édition électronique

URL : http://journals.openedition.org/ifha/2157

DOI : 10.4000/ifha. 2157

ISSN : 2198-8943

Éditeur

IFRA - Institut franco-allemand (sciences historiques et sociales)

Référence électronique

Ludovic Viallet, « Dauven-van Knippenberg, Carla, Herberichs, Cornelia, Kiening, Christian, Medialität des Heils im späten Mittelalter », Revue de l'IFHA [En ligne], Date de recension, mis en ligne le 01 janvier 2010, consulté le 22 septembre 2020. URL : http://journals.openedition.org/ifha/2157 ; DOI : https:// doi.org/10.4000/ifha.2157

Ce document a été généré automatiquement le 22 septembre 2020.

(CIFHA 


\title{
Dauven-van Knippenberg, Carla, Herberichs, Cornelia, Kiening, Christian, Medialität des Heils im späten Mittelalter
}

\author{
Ludovic Viallet
}

1 Les travaux sur la communication sont actuellement très prisés dans le champ de la médiévistique germanophone. Souvent stimulants, ils peuvent un peu désarçonner les chercheurs français par certaines approches indissociables de la malléabilité même de la langue allemande, avec laquelle sont forgés nombre de concepts difficilement traduisibles. En témoigne, à sa façon, l'introduction de Christian Kiening au volume rassemblant les contributions d'un colloque tenu à Zug du 8 au 10 septembre 2008. Elle se clôt en précisant que leur démarche n'est pas celle de la sociologie des religions, mais plutôt de l'histoire des textes, des images et de la «médialité ». Voici donc un livre consacré à l'entre-deux : entre la présence et l'absence, l'ici-bas et l'au-delà, l'immanence et la transcendance. Le terme même de Heil comporte une ambiguïté, que la première étude tente de dissiper : "Médialité du Salut " ? Mais dans la béatitude éternelle qu'est le Salut, il n'y a plus de médialité ; celle-ci réside dans la Miséricorde divine, la Grâce, que les hommes de la fin du Moyen Âge ont conçue dans une proximité croissante par le biais de contacts plus intensifs, plus fréquents, plus directs. C'est ce que B. Hamm désigne par «médialité de la Grâce » (Gnadenmedialität), dont il propose une typologie fondée sur de beaux exemples iconographiques privilégiant la dévotion au Christ et à son corps. Les treize contributions rassemblées ensuite sont autant d'études de cas prenant le texte ou l'image comme moyen de communication avec le divin.

2 Puisque, selon la formule d'H. Schlie dans son étude sur la Vera Ikon, le Moyen Âge a été « moins caractérisé par une culture de la présence que par une culture de l'entredeux, de la tension entre présence et représentation » (p. 70), il s'est agi pendant des siècles de rendre compte de l'absence, de représenter l'invisible et le Mystère. D. Ganz 
analyse la construction de l'image de la stigmatisation de Catherine de Sienne. B. Dümpelmann et $\mathrm{B}$. Dieterich s'intéressent à la mise en scène de l'absence, la première à travers la fonction du linceul dans les images et lors de la fête de Pâques, la seconde à partir des sculptures figurant sur la réplique du Saint-Sépulcre de la cathédrale de Constance (Xe siècle). Enfin, dans les deux dernières études du volume, C. Dauven-Van Knippenberg et $\mathrm{E}$. Meyer étudient un corpus de Concordances évangéliques composées dans les espaces néerlandophone et germanophone à la fin du Moyen Âge, tandis qu'A. Schiffhauer s'intéresse aux vitraux et à la conception qu'en révèlent des sources des IXe-XIIIe siècles, en particulier des vies de saints.

D'autres contributions sont davantage centrées sur les processus mis en œuvre afin de stimuler la mémoire et la dévotion. M. Rimmele cherche ainsi à cerner le rôle des diptyques et triptyques de petites dimensions, donc des charnières guidant et déterminant l'accès des fidèles à des scènes de la Passion. Plusieurs études sont consacrées à des manuscrits issus du réseau des Lüneburger Klöster : les livres de prière de l'abbaye des cisterciennes de Medingen, dans lesquels H. Lähnemann analyse les récits d'apparition du Christ après Pâques et qui servent aussi de support, à côté de l'œuvre de Jean Mombaer, au propos d'U. Hascher-Burger sur le rôle de la musique dans la méditation de la devotio moderna ; le recueil d'allégorèses de la messe des cisterciennes de Wienhausen composé peu après 1300, analysé par T. Mattern comme un medium devant enclencher autre chose que la seule fonction d'explication. Dans les livres de prière de l'abbaye des bénédictines d'Engelberg (J. Thali), dans la cinquantaine de sermons de la seconde moitié du XIVe siècle issus de cette maison (R. Wetzel) ou le Leben Jesu du XVe siècle longtemps attribué à la cistercienne de Lichtenthal Schwester Regula (S. Griese), l'enjeu majeur a été celui de la « production de présence »- selon le concept de Hans Ulrich Gumbrecht placé au cœur de leur approche par plusieurs contributeurs. De fait, ce volume offre un spectre très large pour saisir la diversité des moyens et des vecteurs avec lesquels les médiévaux ont cherché à rendre compte, icibas, de réalités supérieures.

4 Ludovic Viallet (Université Blaise-Pascal Clermont-Ferrand II) 